\title{
Source country characteristics and immigrants' optimal migration duration decision
}

\author{
Murat G Kırdar
}

\section{Correspondence:}

kirdar@metu.edu.tr.

Department of Economics, Middle

East Technical University, Ankara,

06800, Turkey

\begin{abstract}
This paper examines how immigrants' optimal migration duration in the host country responds to the purchasing power parity (ppp) and relative wages between the host and source countries. A theoretical model of joint migration duration and saving decisions reveals that the optimal migration duration decreases in ppp unless the elasticity of intertemporal substitution of consumption is well above typical estimated values for this parameter. In fact, empirical results from immigrants in Germany reveal that optimal migration duration decreases in ppp. The empirical findings also imply that-holding individual immigrant characteristics constant — immigrants from poorer source countries have shorter predicted migration duration than immigrants from wealthier source countries. In addition, this paper shows that longitudinal data on intentions can be informative by examining how observed event realizations lead to revisions to intentions.
\end{abstract}

JEL classification codes: F22, J61

Keywords: Migration duration, Purchasing power parity, Relative wages, Migrants' return intentions

\section{Introduction}

The return of immigrants back to their home countries-so called return migrationhas been significant in many immigration contexts. For instance, while about 800,000 migrants entered Germany on average annually between 1962 and 2005, more than 560,000 left (German Federal Statistics Office); Jasso and Rosenzweig (1982) report that of the 1971 cohort of immigrants in the U.S., the fraction that returned by 1979 could be as high as fifty percent; Aydemir and Robinson (2008) calculate an out-migration rate of 35 percent by 20 years of residence for working-age male immigrants in Canada.

Immigrants' return migration behavior, along with their saving decisions in the host country, has important implications for their home countries. McCormick and Wahba (2001) and Demurger and $\mathrm{Xu}$ (2011) find that the probability of entrepreneurship among return migrants in Egypt and China, respectively, increases in their accumulated savings in the host destinations. Sinning (2011) report, for immigrants in Germany, that return intentions have a positive effect on financial transfers to home country. Return migrants could benefit their home countries also through the transfer of human capital they acquire in the host country. In fact, Dos Santos and Postel-Vinay (2003) show that return migration can contribute to the source country economy through knowledge diffusion, and

(c) 2013 Kırdar; licensee Springer. This is an Open Access article distributed under the terms of the Creative Commons Attribution License (http://creativecommons.org/licenses/by/2.0), which permits unrestricted use, distribution, and reproduction in any medium, provided the original work is properly cited. 
Mayr and Peri (2009) find that return migration could turn brain drain into brain gain in the context of intra-European migration. Non-economic benefits of return migration have also been reported in the literature; for instance, Batista and Vicente (2011) find that migrants who return from countries with good governance improve governance in their home countries. Finally, return migration behavior has important implications for the host country as well. For instance, Kirdar (2012) finds that immigrants' net contributions to the German social security system are substantially influenced by their return migration behavior.

This paper examines how purchasing power parity (ppp) and relative wages between the host and source countries influence immigrants' optimal migration duration in the host country. While some immigrants originate from poor countries, other immigrants come from countries with relatively similar characteristics to those of the host country. For instance, are intra-European immigrants from high wage and low ppp countries or immigrants from developing countries with low wage and high ppp more likely to stay longer? Moreover, while some developing source countries maintain long periods of economic growth, others are hit by occasional economic crisis, which sometimes result in substantial changes in ppp and wage ratio between the host and source countries. For instance, ppp between Germany and Turkey increased by 35 percent in the aftermath of the 1994 financial crisis in Turkey.

Using a model of joint consumption and migration duration decisions, I first examine the impact of ppp and relative wages on the optimal migration duration decision of immigrants. Then, in the empirical part of the paper, I test the implications of the theoretical model using a rich longitudinal data set on immigrants from four source countries (Greece, Italy, Spain, and Turkey) in Germany. The empirical context is appropriate for testing the hypotheses derived from this theoretical model because the empirical literature has provided ample evidence on the savings accumulation motivation for immigrants originating from these Mediterranean countries in Germany. Paine (1974) and Kumcu (1989) report saving rates in excess of 35 percent for Turkish immigrants in their first few years in Germany.

The theoretical part of the paper shows that the effect of ppp on optimal migration duration is negative unless the elasticity of intertemporal substitution of consumption is well above the empirically-established levels. However, in the case that immigrants do not plan to work after returning to their home countries - which is empirically relevant in certain contexts, the effect of ppp on optimal migration duration is always negative (regardless of the elasticity of intertemporal substitution of consumption).

The major contribution of this paper is empirical. While Yang (2006) and Kirdar (2009) uncover empirical evidence on the effect of ppp on return migration rates, this study provides the first empirical evidence, to the best of my knowledge, on the effect of ppp on the migration duration in the host country. The empirical results reveal that the impact of ppp on optimal migration duration is negative and large; for instance, a 10 percent increase in ppp lowers the migration duration of a 20-year-old arriver by 20 percent. This paper also provides an empirical answer for the first time, in the German context, to an important question posed by Stark et al. (1997): is it possible that immigrants from poorer source countries stay shorter in the host country? This is, in fact, the case in the German context; immigrants facing Turkish ppp and relative wage values have a shorter predicted migration duration than immigrants facing 
the ppp and relative wage values of wealthier EU countries in the sample, when all other characteristics of immigrants are the same.

Finally, this study also shows that data on individuals' revisions to intentions can be valuable. Manski (2004) claims that, "Research that measures revisions to expectations and associates them with observed event realizations can be informative ${ }^{1}$. In fact, using revisions to intended migration duration over time, as well as observed event realizations, this study shows that the realizations of ppp values lead to revisions to intended migration duration. Moreover, this finding as to the effect of ppp on migration duration, using data on intentions, is consistent with the findings of Kırdar (2009), who investigates the same relationship using actual realizations of return migration ${ }^{2}$.

The next section reviews the related literature. Section 3 describes the theoretical model, and Section 4 explains the data. The estimation method is covered in Section 5, and the empirical results are presented in Section 6. Section 7 concludes.

\section{Relevant literature}

Immigration decision is rationalized in income-maximizing models by higher wages in the host countries (Sjastaad 1962, Harris and Todaro 1970). According to these models, an immigrant would not return to his/her home country unless there is a reversal of wage levels in the host and source countries or unless his/her earning realization at the destination turns out to be much lower than the expected earnings at the destination before arrival ${ }^{3}$. Return migration could be explained as part of optimal life-cycle location decisions: at the time of immigration, migrants realize that after they acquire physical or human capital in the host country, it may be optimal for them to return because the returns to that type of capital are higher in the home country (see, for example, Djajic and Milbourne 1988, Djajic 1989, Stark et al. 1997, Dustmann 2003). If the home country has lower prices, the savings that immigrants accumulate in the host country have higher purchasing power at home. This is how return migration is motivated in this paper.

In this framework of saving accumulation and return migration, two important determinants of migrants' saving and return choices are purchasing power parity and relative wages between the host and source countries. Stark et al. (1997) examine the theoretical impact of ppp, as well as source and host country wage levels, on optimal migration duration in this framework of joint consumption and migration duration decisions. Using a logarithmic utility function in their analysis, Stark et al. find a negative impact of ppp on migration duration. On the other hand, my model allows for a more general utility function, where there is a parameter governing the willingness to substitute consumption intertemporally. According to what the previous empirical studies have uncovered regarding the elasticity of intertemporal substitution of consumption, my model also implies that the optimal migration duration decreases in ppp, as found by Stark et al.

Djajic and Milbourne (1988) also builds a model of joint migration duration and saving decisions; however, in their model, the reason for immigrants' return to their home country is higher marginal utility of consumption in their home country. In other words, they do not account for the higher purchasing power of the savings accumulated in the host country. In this framework, they examine the effect of wage levels in either country on the optimal migration duration and the consumption level in the host country. Purchasing power parity, as well as elasticity of intertemporal substitution of consumption, is 
part of the analysis of saving decisions of guestworkers in Djajic (1989); however, optimal migration duration is not a choice variable in this study.

The previous empirical literature (for example; Yang 2006, Kırdar 2009) has established certain causal links between the purchasing power of immigrants and their return migration behavior. Unlike this previous literature, which uses data on return migration realizations, this study uses longitudinal information on intended migration durations. This longitudinal information allows the use of fixed-effects estimation methods, which eliminate the unobserved heterogeneity in immigrants' time-invariant characteristics, whereas this is not the case in the other two papers. In addition, the scope of the empirical part of this paper is wider in that it also examines the impact of relative wages on migration duration.

The empirical literature on migration boasts evidence that immigrants in several parts of the world have a savings accumulation motivation. For instance, Yang (2006) shows that return migration of Philippine migrants depends on the exchange rate with the host countries, and Massey and Espinosa (1997) find that return migration of Mexican immigrants in the U.S. responds to prices in Mexico. Therefore, the findings of this paper within a savings accumulation model have applicability to a much wider context.

\section{Model}

\subsection{Basic structure}

At the time of arrival to the host country, immigrants choose their optimal migration duration $(d)$ and consumption levels in the host and source countries $\left(c_{1}, c_{2}\right)$ according to the following problem:

$$
\begin{array}{rl}
\max _{d, c_{1}, c_{2}} & d u\left(c_{1}\right)+(\tau-d) u\left(c_{2}\right) \\
\text { s.t. } & p d c_{1}+(\tau-d) c_{2} \leq p d y_{g}+(\tau-d) y_{h}, \\
& y_{g} \geq c_{1} \geq 0, \quad \tau \geq d \geq 0 .
\end{array}
$$

In (3.1), $\tau$ denotes the remaining lifetime at the time of arrival to the host country. Immigrants' preferences depend on consumption according to a per-period utility function, $u($.$) . The utility maximization problem of immigrants is subject to a number of$ constraints. The first one is a lifetime budget constraint, where $p$ denotes the purchasing power parity between the host and home countries, $y_{g}$ the real wage rate in the host country, and $y_{h}$ the real wage rate in the home country. The second and third constraints are boundary conditions for the consumption choice in the host country and migration duration choice, respectively.

In the above problem, purchasing power parity is taken to be greater than one $(p>1)$ and the real wage rate in the host country is higher than the real wage rate in the home country $\left(y_{g}>y_{h}\right)$. While the former assumption is required to rationalize the return migration decision, the latter condition is the reason why these foreign workers are in the host country. I choose a constant relative-risk aversion utility function,

$$
\begin{gathered}
\mathrm{u}(c)=c^{\alpha} / \alpha \quad \alpha<1, \alpha \neq 0 \\
\ln (c) \quad \alpha=0
\end{gathered}
$$


because this functional form allows me to examine how the effects of ppp and relative wages on the optimal migration duration and consumption decisions of immigrants vary by the curvature of the utility function (or by immigrants' willingness to substitute consumption intertemporally). The elasticity of intertemporal substitution of consumption is $1 /(1-\alpha)$.

\subsection{Solution of the problem}

Assuming an interior optimal solution, the decision rule for the optimal migration duration in the host country can be written as follows:

$$
d^{*}=\frac{\tau\left[(1-\alpha) p^{\alpha /(\alpha-1)}\left(y_{h} / y_{g}\right)+\alpha p-\left(y_{h} / y_{g}\right)\right]}{\left(1-p^{\alpha /(\alpha-1)}\right)\left[p-\left(y_{h} / y_{g}\right)\right]} .
$$

Note that the optimal migration duration, $d^{*}$, depends on the ratio but not the level of wages $^{4}$.

\subsection{Comparative statics}

Here, I illustrate how the optimal migration duration responds to changes in purchasing power parity and relative wages.

\subsubsection{Effect of purchasing power parity on migration duration}

The partial derivative of optimal migration duration with respect to ppp is given by

$$
\begin{aligned}
& \frac{\partial d^{*}}{\partial p}=\frac{\tau}{(\alpha-1)\left(y_{h} / y_{g}-p\right)^{2} p\left(p^{\frac{\alpha}{\alpha-1}}-1\right)^{2}} * \\
& \left\{-(\alpha-1)^{2}\left(y_{h} / y_{g}\right)\left(p^{1 / 2}-p^{\frac{3 \alpha-1}{2(\alpha-1)}}\right)^{2}-2 \alpha^{2} p^{\frac{2 \alpha-1}{\alpha-1}}\left(y_{h} / y_{g}\right)+p^{\frac{3 \alpha-2}{\alpha-1}} \alpha^{2}+p^{\frac{\alpha}{\alpha-1}} \alpha^{2}\left(y_{h} / y_{g}\right)^{2}\right\} \lesseqgtr 0 .
\end{aligned}
$$

The sign of $\partial d^{*} / \partial p$ is analytically ambiguous as the first two terms inside the curly brackets are negative whereas the last two are positive; therefore, I evaluate it numerically for various values of the source country paramaters ( $p$ and $y_{h} / y_{g}$ ) and the parameter that governs immigrants' willingness to substitute consumption intertemporally $(\alpha)$. In doing so, I select the values of the wage ratio and ppp such that they reflect the range of these variables for the source countries in the sample. The numerical results reveal that the sign of $\partial d^{*} / \partial p$ can be positive only for very high values of willingness to substitute consumption intertemporally. For instance, when the wage ratio and the purchasing power parity are set at 0.5 and 1.5, respectively, the sign of $\partial d^{*} / \partial p$ is negative for all values of $\alpha$ below 0.94 ; and when they are set at 0.25 and 2.5 , respectively, the sign of $\partial d^{*} / \partial p$ is negative for all values of $\alpha$ below 0.87 . Thus, given the values of the elasticity of intertemporal substitution of consumption estimated in the literature, we can claim that the sign of $\partial d^{*} / \partial p$ would be negative ${ }^{5}$. Hence, the finding of Stark et al. (1997) that there is a negative relationship between ppp and the optimal migration duration when the utility function has a logarithmic form can be generalized to all CRRA-type utility functions with a curvature parameter that is empirically relevant.

There are two separate effects of an increasing ppp. On one hand, the value of accumulated savings after returning to the home country increases; therefore, immigrants want to spend a larger fraction of their lifetime in their home country (income effect). On the 
other hand, the returns to staying longer in Germany and accumulating more savings also increase (substitution effect). Immigrants who are more willing to substitute consumption intertemporally (with a higher $\alpha$ ) are, by definition, more patient about saving in the host country in order to enjoy its benefits in the form of high consumption after return. Therefore, the increase in the opportunity cost of return resulting from a rise in ppp is higher for them. There is also an indirect effect resulting from the change in consumption behavior. A higher ppp increases the saving rate in the host country. As a result, immigrants accumulate savings faster and the income effect becomes stronger. This indirect effect, which decreases optimal migration duration, is weaker for immigrants who are more willing to substitute consumption intertemporally because these immigrants already save more (due to their higher willingness to substitute consumption intertemporally); therefore, there is less room for an increase in their savings. Therefore, as the numerical analysis indicates, the income effect dominates the substitution effect unless the elasticity of intertemporal substitution of consumption is unrealistically high.

Proposition 1. The impact of purchasing power parity on optimal migration duration is negative (unless the elasticity of intertemporal substitution of consumption is much higher than those that have been estimated in the literature).

Special Case: $y_{h}=0$ Next, I investigate how immigrants' optimal migration duration and consumption decisions respond to ppp when they do not intend to work as wage earners after returning to their home country. This restriction allows drawing more general conclusions regarding the impact of ppp on optimal migration duration. However, it is not a restriction made only for tractability; it has empirical relevance as well. Dustmann and Kirchkamp (2002) report, based on a sample of return migrants from Germany in Turkey, that many migrants return home to enjoy retirement at a lower cost of living. When immigrants do not plan to work as wage earners in their home country after return, the partial derivative of the optimal migration duration with respect to ppp is given by

$$
\frac{\partial d^{*}}{\partial p}=\frac{\tau p^{\frac{1}{\alpha-1}} \alpha^{2}}{(\alpha-1)\left(p^{\frac{\alpha}{\alpha-1}}-1\right)^{2}}<0 .
$$

Proposition 2. When immigrants do not plan to work as wage-earners after returning to their home country, optimal migration duration decreases in purchasing power parity (regardless of the elasticity of intertemporal substitution of consumption).

\subsubsection{Effect of relative wages on migration duration}

The marginal of the optimal migration duration with respect to the wage ratio is as follows:

$$
\frac{\partial d^{*}}{\partial\left(y_{h} / y_{g}\right)}=\frac{p \tau(\alpha-1)}{\left[p-\left(y_{h} / y_{g}\right)\right]^{2}}<0 .
$$

Proposition 3. As the ratio of home country wage rate to host country wage rate increases, the optimal migration duration decreases ${ }^{6}$. 


\section{Data}

The data set used in this study is the German Socioeconomic Panel (GSOEP). I use the 2000 version of GSOEP, which includes annual surveys from 1984 to 2000 . The nice feature of this data set is that it contains an over-sampled group of immigrants from five different source countries: Turkey, ex-Yugoslavia, Greece, Italy and Spain. I do not include the ex-Yugoslavian immigrants in this study due to the split of the original country into numerous new countries during the time frame of this study. Many of these immigrants arrived in Germany in the 1960's and 1970's under the bilateral agreements signed by these source country governments with the German government (guestworker recruitment scheme). The immigrant panel of the GSOEP starts with a representative sample of the stock of immigrants from these source countries in Germany in 1984.

Immigrants' return intentions are examined at each survey year by two separate questions. First, immigrants are asked whether or not they plan to return to their home country, which I use to construct a dummy variable for return intention. This dummy variable takes the value of 1 when the immigrant plans to return, and 0 otherwise. Immigrants who report a return intention are next asked about their intended duration of residence in Germany (in number of years). For immigrants who do not intend to return to their home country, I take the intended duration of residence as equal to the remaining lifetime. I assume that immigrants live until age 80 because this is the maximum value of age observed in the data.

The sample is restricted to households with a male household head who was 18 or older at arrival. This age restriction is made because these immigrants must have made the initial in-migration decision themselves given the interpretation of return migration as part of optimal life-cycle migration decisions in the underlying model that is tested. This restriction reduces the sample to 828 male household heads, of whom 827 provide information on the return intention dummy variable for at least one year. Therefore, the final sample includes 827 male household heads, of which 311 are Turkish, 156 are Greek, 212 are Italian, and 148 are Spanish.

Panel (a) of Table 1 provides descriptive statistics for the 827 people in the sample. The mean age at arrival is 28.5; and the mean duration of residence in 1984 is about 15 years, however there are immigrants in the sample who we observe immediately after arrival. The immigrants in the sample are observed for an average duration of roughly 8 years (after 1984). When I examine the longitudinal structure of the return intention dummy variable for these 827 people, I find that less than 8 percent (65 people) always report of an intention to stay, roughly 43 percent (357 people) always report a return intention, and the rest revise their return intentions over time.

A number of individual-level characteristics of these immigrants are used in the empirical analysis: these include age, duration of residence, nationality, educational attainment (high school and college graduation status), marital status, and year of arrival (dummy variable for arrival after 1973-the last year of guestworker recruitment). Panel (b) of Table 1 provides descriptive statistics for these variables over the 7,154 person-year observations in the data. (For the 827 people in the sample, the dummy variable for return intention is available for 7,154 person-year observations.) 
Table 1 Descriptive statistics for micro-level control variables

\begin{tabular}{lccccc}
\hline A) Person level characteristics & No. obs. & Mean St. & Dev. & Min & Max \\
\hline Age at arrival & 827 & 28.48 & 6.82 & 18 & 49 \\
Years of residence at 1984 & 827 & 15.66 & 5.42 & 1 & 32 \\
Years of residence until last survey & 827 & 23.74 & 8.31 & 1 & 48 \\
\hline B) Person-year level characteristics & & & & \\
\hline & No. obs. & Mean St. & Dev. & Min & Max \\
\hline Age & 7154 & 49.82 & 9.41 & 20 & 80 \\
Duration of residence (years) & 7154 & 21.85 & 7.05 & 1 & 48 \\
High school graduate & 7154 & 0.17 & 0.37 & 0 & 1 \\
College graduate & 7154 & 0.04 & 0.19 & 0 & 1 \\
1974-83 Cohort & 7154 & 0.11 & 0.31 & 0 & 1 \\
Greek & 7154 & 0.20 & 0.40 & 0 & 1 \\
Italian & 7154 & 0.26 & 0.44 & 0 & 1 \\
Spanish & 7154 & 0.14 & 0.35 & 0 & 1 \\
Married & 7154 & 0.88 & 0.33 & 0 & 1 \\
\hline
\end{tabular}

For 4,779 of the 7,154 person-year observations in the data (about two thirds), the return intention dummy variable takes the value of 1 . Out of these 4,779 observations in which a return intention is indicated, information on the intended duration of residence is available for 3,724. Among these 3,724 observations on intended duration for residence, almost 8 percent are return intentions within 12 months, 55 percent are return intentions within the next 5 years, and 88 percent are return intentions within the next 10 years. Since I generate the intended duration of residence for the 2,375 observations in which a stay intention is reported (by using the remaining lifetime), there are a total of 6,099 nonmissing observations on intended duration of residence. Of the 827 people for whom the return intention dummy variable is available, information on intended migration duration is available for 813 .

Figure $1 \mathrm{a}$ and $1 \mathrm{~b}$ display how the mean value for the return intention dummy variable changes by duration of residence and age, respectively. The profiles for the mean remaining intended duration of residence by current duration of residence and age are given in Figures $1 \mathrm{c}$ and $1 \mathrm{~d}$, respectively.

The two key variables in this study are macro-level variables: purchasing power parity and wage ratio, which exhibit variation across countries of origin and calendar years ${ }^{7}$. There is substantial variation in ppp levels across source countries; the average ppp, over the 17 years, for Turkish immigrants is roughly twice as much as that for Italian immigrants. The variation in ppp over time is also significant; in fact, it is remarkable for Turkish immigrants: there was a 35 percent rise in 1994, the year of an economic crisis, as well as a 34 percent rise in 1986 .

\section{Estimation}

This section presents the estimation method used in testing the comparative statics implications of the theoretical model regarding the effects of ppp and wage ratio on the optimal migration duration, given in propositions 1 and 2 . Since the model's predictions are given for the time of arrival whereas in the data immigrants are observed at various times after 


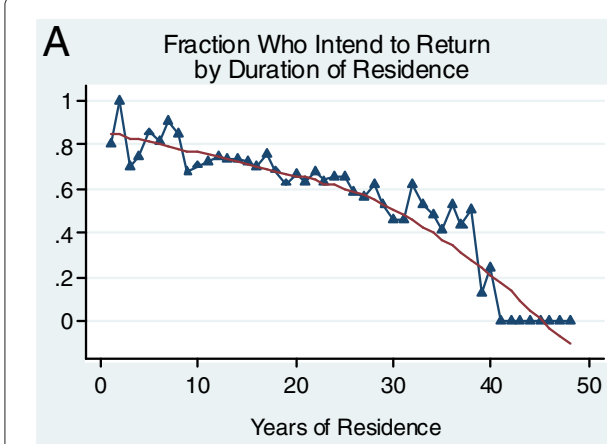

C Mean Remaining Intented Duration of Residence

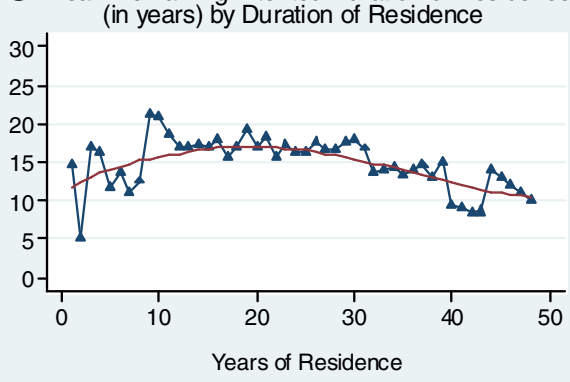

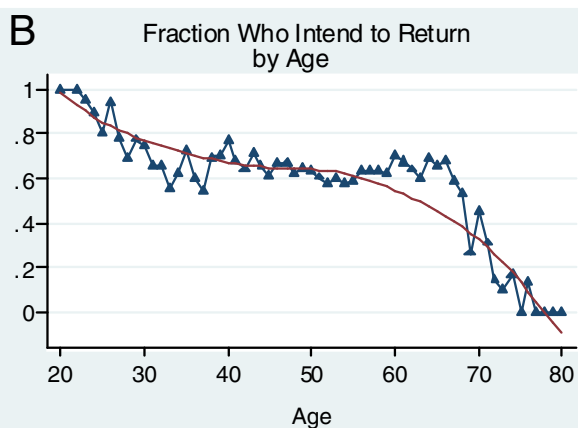

D Mean Remaining Intented Duration of Residence

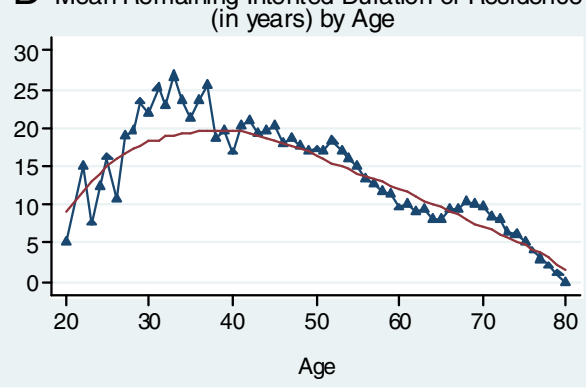

Figure 1 Intention to Return by Duration of Residence (Panel A) and by Age (Panel B), Remaining Intended Duration of Residence by Duration of Residence (Panel C) and by Age (Panel D).

arrival, this section also explains in detail how the predictions of the model are matched with the data.

The optimal migration duration, $d^{*}$, in (3) can be written in the following functional form:

$$
d^{*}=d\left(\tau, p, y_{h} / y_{g} ; \alpha\right) .
$$

I approximate the functional form in (7) using a linear model in the estimation. In (7), the optimal migration duration depends on age (in other words, the remaining lifetime $[\tau])$, in addition to the two key macroeconomic variables and the curvature parameter. Moreover, the impacts of ppp and wage ratio on the optimal migration duration vary by age, as can be seen in (4) and (6). Therefore, the empirical specification optimal migration duration, $d$, is given by

$$
d_{i}=\beta_{0}+\beta_{1} \text { ppp }_{i}+\beta_{2} \text { ppp }_{i} \text { age }_{i}+\beta_{3} \text { wage }_{i}+\beta_{4} \text { wage }_{i} a_{g e}+\beta_{5} \text { age }_{i}+X_{i} \Gamma+u_{i},
$$

where $X$ stands for the other factors that influence migration duration and saving decisions, like individual shifters in the utility function (for example, marital status).

The theoretical model's predictions are for the time of arrival; and, accordingly, all variables in (8) are written for the time of arrival for each person i. However, the data include information on intended migration duration not at arrival, but at various years after arrival. Therefore, a time index $(t)$ is introduced in the longitudinal structure of the data as follows:

$$
\begin{aligned}
d_{i t}= & \beta_{0}+\beta_{1} \text { ppp }_{i t}+\beta_{2} \text { ppp }_{i t} \text { age }_{i t}+\beta_{3} \text { ppp }_{i t} t_{i}+\beta_{4} \text { wage }_{i t}+\beta_{5} \text { wage }_{i t} \text { age }_{i t} \\
& +\beta_{6} \text { wage }_{i t} t_{i}+\beta_{7} \text { age }_{i t}+\beta_{8} \text { age }_{i t} t_{i}+\beta_{9} t_{i}+X_{i t} \Gamma+u_{i t} .
\end{aligned}
$$


In (9), $t$ stands for duration of residence; and intended migration duration is allowed to vary by duration of residence, as well as by the interaction of duration of residence with age. In addition, ppp and wage ratio are interacted with duration of residence, which allows the estimation of the effects of these key variables conditional on duration of residence. When duration of residence ( $t$ ) is zero, equation (9) reduces to equation (8); in other words, when $t$ is zero, the empirical model matches the theoretical model. Therefore, the results from the empirical model at zero duration of residence are used to test the implications of the theoretical model in the next section.

The repeated observations on intended migration duration allow the estimation of (9) using a fixed-effects OLS estimator. This is very important because the nature of the data forces us to condition on duration of residence. However, controlling for duration of residence in a cross-section regression of (9) would be problematic because permanent unobserved characteristics of immigrants (like preferences) in the error term in (9) would influence both duration of residence $\left(t_{i}\right)$ and intended migration duration $\left(d_{i t}\right)$, resulting in biased estimates. Using fixed-effects estimation allows the elimination of this bias that would be caused by permanent unobserved characteristics of immigrants by differencing them out ${ }^{8}$. The identification of the parameters of the key variables of interest comes from immigrants' revisions to intended migration duration as a result of observed changes in ppp and wage ratio over time.

Weighted regressions are used in the fixed-effects OLS estimation of (9) using the sampling weights for 1984. About the macro variables in (9), it is assumed that immigrants make their projections based on the average of the actual values of these variables in the last three years. Since the macro-level variables used in the estimation do not exhibit variation across people from the same source country in a given year, standard errors are calculated by clustering at the level of country of origin. However, as the number of clusters is small, even cluster-robust standard errors may lead to downward-biased standard errors (Cameron et al. 2008). Therefore, I use a T-distribution with 3 degrees of freedom in finding the significance levels, as suggested by Cameron et al. as a minimum requirement for dealing with the issue of few clusters.

\subsection{Specification checks}

I use four additional specifications to check the robustness of the findings from the estimation of (9). In the second specification, I drop the interaction term of ppp with age and the interaction term of wage with duration of residence so that I can draw more general conclusions regarding the effects of ppp and wage ratio variables. However, the interaction of ppp with duration of residence is kept because the same amount of change in ppp would surely alter the migration duration of a new arriver and an immigrant with 20 years of residence differently; similarly, the interaction of wage ratio with age is kept because the effect of expected wages obviously depends on age. In the third specification, I also eliminate the interaction term of ppp with duration of residence; now, ppp enters the specification only by itself. However, in this case, I place restrictions on the sample according to duration of residence in 1984 in order to have a more homogenous initial sample.

In the fourth and fifth specifications, I check the robustness of my findings to possible omitted variables that might be correlated with the key variables of interest. A change in ppp could arise from events in Germany as well as the source countries. When the change arises from an event in Germany, it is common to all observations. Moreover, this event 
in Germany could change other variables that also have an impact on the dependent variable. In this case, if these other variables are not accounted for in the regression, ppp would in part stand for these variables, resulting in an omitted variables bias. For instance, suppose that an economic downturn in Germany brings about a rise in prices, altering the ppp with the source countries. This economic downturn could also cause an upsurge in the anti-immigrant sentiment in Germany, which would presumably change immigrants' migration duration and saving choices. However, not accounting for anti-immigrant sentiment, we would mistakenly attribute any change in immigrants' migration duration and saving choices to the change in ppp. For this reason, I add calendar-year dummies to (9) in the fourth specification.

Similarly, there may be other time-varying factors in the source countries that are correlated with ppp or wage ratio and that also affect return migration and saving decisions. For instance, economic growth could affect the currency of the home country and, therefore, ppp as well. At the same time, economic growth in the home country could influence immigrants' return decision. Therefore, not accounting for it could also cause an omitted variable bias. For this reason, in the fifth specification, I also add controls for the growth rate in the source countries as well as its interactions with age and duration of residence, in addition to calendar year dummies, to (9).

\section{Empirical results}

The results of fixed-effects OLS regression of intended migration duration are presented in Table 2 for specifications 1, 2, 4, and 5. Since the key variables of interest are interacted with age and duration of residence, the impacts of these variables are presented in Table 3 at zero years of residence (at the time of arrival) and at 20 years of residence (roughly the mean value in the data for this variable) for selected values of age ${ }^{9}$.

The estimated parameters for the time of arrival, presented in panel (a) of Table 3, are used to test the predictions of the model. An increase in ppp lowers the optimal migration duration at the time of arrival in Germany, regardless of the age at arrival in specifications 1 and 2. The negative effect of ppp on optimal migration duration is robust to the addition of calendar year dummies, as well as the controls for the home country growth rate, as can be seen in specifications 4 and 5 . However, with these additional controls, both the magnitude and statistical significance of the effect of ppp diminish. Yet, the magnitude of the effect remains large in all specifications, and the statistical significance is at least at the 10 percent level for all immigrants aged 29 or older at arrival in specification 4 and for all immigrants aged 34 or older at arrival in specification 5.

The effect of ppp on the optimal migration duration at the time of arrival is large; for instance, according to the first specification, a 10 percent increase in ppp lowers the optimal migration duration of a 20 -year-old arriver by 1.8 years. Since the predicted migration duration for an average unmarried 20-year-old arriver in 1984 (at average ppp and wage ratio values for 1984) is 9.0 years, a 10 percent increase in ppp reduces the optimal migration duration of this immigrant by 20 percent. The effect of ppp is even larger for an unmarried 30-year-old arriver in 1984: according to the first specification, a 10 percent increase in ppp reduces his optimal migration duration by 2.4 years, which implies a 38 percent fall from an initial duration of 6.3 years.

In specifications 1, 4, and 5-where the effect of ppp is allowed to vary by age-both the statistical significance and the magnitude of the coefficient for ppp are lower for younger 
Table 2 Fixed-effects OLS estimates for intended migration duration

\begin{tabular}{|c|c|c|c|c|}
\hline \multicolumn{5}{|c|}{ Dependent variable: intented migration duration } \\
\hline & Specification 1 & Specification 2 & Specification 4 & Specification 5 \\
\hline \multirow[t]{2}{*}{ Log(PPP) } & -6.146 & $-25.378^{* * *}$ & 5.020 & 9.518 \\
\hline & [11.295] & {$[4.176]$} & [11.571] & [9.888] \\
\hline \multirow[t]{2}{*}{$\log (P P P) *$ age } & -0.595 & & $-0.630^{*}$ & $-0.664^{* *}$ \\
\hline & [0.293] & & {$[0.236]$} & [0.192] \\
\hline \multirow[t]{2}{*}{$\log (P P P) *$ dur. of res. } & $1.547^{* *}$ & $1.075^{* * *}$ & $1.473^{* *}$ & $1.466^{* *}$ \\
\hline & {$[0.368]$} & {$[0.178]$} & {$[0.426]$} & {$[0.420]$} \\
\hline \multirow[t]{2}{*}{ Wage ratio } & -7.267 & -14.248 & -6.354 & -2.317 \\
\hline & {$[9.344]$} & [12.024] & [14.064] & [16.749] \\
\hline \multirow[t]{2}{*}{ Wage ratio * age } & 0.017 & 0.100 & -0.068 & -0.142 \\
\hline & [0.303] & {$[0.268]$} & {$[0.244]$} & {$[0.320]$} \\
\hline \multirow[t]{2}{*}{ Wage ratio * dur. of res. } & -0.114 & & 0.440 & 0.542 \\
\hline & {$[0.556]$} & & {$[0.903]$} & {$[0.777]$} \\
\hline \multirow[t]{2}{*}{ Dur. of residence } & $2.748^{* *}$ & $2.712^{* * *}$ & $3.533^{* * *}$ & $3.830^{* * *}$ \\
\hline & {$[0.553]$} & [0.322] & {$[0.240]$} & {$[0.384]$} \\
\hline \multirow[t]{2}{*}{ Age $^{*}$ dur. of residence } & $-0.031^{* *}$ & $-0.032^{* * *}$ & $-0.032^{* * *}$ & $-0.034^{* * *}$ \\
\hline & {$[0.005]$} & [0.003] & {$[0.005]$} & {$[0.005]$} \\
\hline \multirow[t]{2}{*}{ Married } & $-2.587^{* *}$ & $-2.477^{* *}$ & $-2.615^{* *}$ & $-2.623^{*}$ \\
\hline & {$[0.713]$} & {$[0.694]$} & {$[0.821]$} & [0.829] \\
\hline \multirow[t]{2}{*}{ Home country growth rate } & & & & 2.101 \\
\hline & & & & [0.988] \\
\hline \multirow[t]{2}{*}{ Home country growth rate ${ }^{*}$ age } & & & & -0.029 \\
\hline & & & & {$[0.014]$} \\
\hline \multirow[t]{2}{*}{ Home country growth rate ${ }^{*}$ dur. of res. } & & & & -0.021 \\
\hline & & & & {$[0.009]$} \\
\hline Year dummies & No & No & Yes & Yes \\
\hline Observations & 6,099 & 6,099 & 6,099 & 6,099 \\
\hline Number of people & 813 & 813 & 813 & 813 \\
\hline R-squared & 0.186 & 0.187 & 0.195 & 0.196 \\
\hline
\end{tabular}

Notes: Standard errrs are adjusted for clustering at the level of country of origin. Macro variables are three-year moving averages. Robust standard errors in brackets; ${ }^{*}$ significant at $10 \% ;{ }^{* *}$ significant at $5 \% ;{ }^{* * *}$ significant at $1 \%$.

arrivers. This is primarily because a larger fraction of younger arrivers plan to stay in Germany throughout their remaining lifetime and for immigrants who do not plan to return to their home country, purchasing power parity would not matter ${ }^{10}$.

Panel (a) of Table 3 also presents the estimated parameters for the effect of ppp on optimal migration duration for immigrants who have already been in Germany for 20 years. We would expect the optimal migration duration of an immigrant who chooses to stay in Germany for 20 years to be less responsive to a change in ppp. In fact, there is no statistically significant evidence, except for older arrivers in specification one, that ppp influences the optimal migration duration of immigrants who have been in Germany for 20 years. Moreover, the magnitudes of the estimated coefficients are much smaller at 20 years of residence compared to those at the time of arrival.

The effect of wage ratio on migration duration decision is displayed in panel (b) of Table 3, also at the time of arrival and at 20 years of residence for various values of age. The coefficient of wage ratio for the time of arrival has a negative sign in all specifications, as predicted by the theoretical model; however, it is statistically significant only in specification 2, which does not include a duration of residence interaction of wage ratio. 
Table 3 Impacts of PPP and wage ratio on intended migration duration at arrival

\begin{tabular}{|c|c|c|c|c|c|c|c|c|}
\hline \multicolumn{9}{|c|}{ (A) Effect of $\log ($ PPP) } \\
\hline & \multicolumn{2}{|c|}{ Specification 1} & \multicolumn{2}{|c|}{ Specification 2} & \multicolumn{2}{|c|}{ Specification 4} & \multicolumn{2}{|c|}{ Specification 5} \\
\hline \multicolumn{9}{|c|}{ Duration of residence $=0$} \\
\hline Age & Coef. & SE & Coef. & SE & Coef. & SE & Coef. & SE \\
\hline 20 & -18.048 & $5.705 *$ & -25.378 & $4.176 * * *$ & -7.584 & 7.115 & -3.765 & 6.858 \\
\hline 25 & -21.024 & $4.419^{* *}$ & -25.378 & $4.176^{* * *}$ & -10.735 & 6.066 & -7.086 & 6.241 \\
\hline 30 & -23.999 & $3.286^{* * *}$ & -25.378 & $4.176^{* * *}$ & -13.886 & $5.075 *$ & -10.407 & 5.720 \\
\hline 35 & -26.975 & $2.523 * * *$ & -25.378 & $4.176^{* * *}$ & -17.038 & $4.184 * *$ & -13.728 & $5.322 *$ \\
\hline 40 & -29.950 & $2.495 * * *$ & -25.378 & $4.176^{* * *}$ & -20.189 & $3.471 * *$ & -17.049 & $5.077 * *$ \\
\hline 45 & -32.926 & $3.222 * * *$ & -25.378 & $4.176^{* * *}$ & -23.340 & $3.064 * * *$ & -20.369 & $5.007 * *$ \\
\hline \multicolumn{9}{|c|}{ Duration of residence $=20$} \\
\hline Age & Coef. & SE & Coef. & SE & Coef. & SE & Coef. & SE \\
\hline 40 & 0.983 & 5.788 & -3.871 & 3.062 & 9.277 & 8.539 & 12.270 & 6.317 \\
\hline 45 & -1.993 & 4.381 & -3.871 & 3.062 & 6.126 & 7.498 & 8.949 & 5.416 \\
\hline 50 & -4.968 & 3.029 & -3.871 & 3.062 & 2.975 & 6.505 & 8.949 & 5.416 \\
\hline 55 & -7.944 & $1.860 * *$ & -3.871 & 3.062 & -0.177 & 5.585 & 2.308 & 3.702 \\
\hline 60 & -10.919 & $1.427 * * *$ & -3.871 & 3.062 & -3.328 & 4.782 & -1.013 & 2.942 \\
\hline 65 & -13.895 & $2.215^{* * *}$ & -3.871 & 3.062 & -6.479 & 4.164 & -4.334 & 2.334 \\
\hline \multicolumn{9}{|c|}{ B) Effect of wage ratio } \\
\hline & \multicolumn{2}{|c|}{ Specification 1} & \multicolumn{2}{|c|}{ Specification 2} & \multicolumn{2}{|c|}{ Specification 4} & \multicolumn{2}{|c|}{ Specification 5} \\
\hline \multicolumn{9}{|c|}{ Duration of residence $=0$} \\
\hline Age & Coef. & SE & Coef. & SE & Coef. & SE & Coef. & SE \\
\hline 20 & -6.928 & 7.020 & -12.247 & 6.682 & -7.705 & 12.342 & -5.167 & 13.375 \\
\hline 25 & -6.843 & 7.160 & -11.747 & 5.355 & -8.043 & 12.182 & -5.879 & 12.895 \\
\hline 30 & -6.758 & 7.606 & -11.247 & $4.039 *$ & -8.381 & 12.144 & -6.591 & 12.601 \\
\hline 35 & -6.673 & 8.309 & -10.747 & $2.748 * *$ & -8.719 & 12.229 & -7.304 & 12.507 \\
\hline 40 & -6.589 & 9.210 & -10.246 & $1.547^{* * *}$ & -9.057 & 12.433 & -8.016 & 12.616 \\
\hline 45 & -6.504 & 10.257 & -9.746 & $0.915 * * *$ & -9.395 & 12.752 & -8.728 & 12.925 \\
\hline \multicolumn{9}{|c|}{ Duration of residence $=20$} \\
\hline Age & Coef. & SE & Coef. & SE & Coef. & SE & Coef. & SE \\
\hline 40 & -8.875 & $2.063^{* *}$ & -10.246 & $1.547 * * *$ & -0.262 & 5.729 & 2.817 & 3.240 \\
\hline 45 & -8.790 & $0.988 * * *$ & -9.746 & $0.915^{* * *}$ & -0.600 & 5.600 & 2.105 & 2.743 \\
\hline 50 & -8.706 & $1.515^{* *}$ & -9.246 & $1.698 * *$ & -0.938 & 5.734 & 1.393 & 3.111 \\
\hline 55 & -8.621 & $2.865^{* *}$ & -8.746 & $2.921 *$ & -1.276 & 6.114 & 0.680 & 4.117 \\
\hline 60 & -8.536 & 4.327 & -8.246 & 4.217 & -1.614 & 6.698 & -0.032 & 5.416 \\
\hline 65 & -8.451 & 5.817 & -7.745 & 5.536 & -1.952 & 7.439 & -0.744 & 6.845 \\
\hline
\end{tabular}

Notes : Estimates are based on the parameters given in Table 2. A t(3) distribution is used in forming the significance levels. *** significant at 1 percent level, ${ }^{* *}$ at 5 percent level, ${ }^{*}$ at 10 percent level.

The significance is lower for age values at which the data are more sparse (lower ages). According to the estimates in specification 2, a 10 percentage point increase in the wage ratio decreases the migration duration of an unmarried 30-year-old arriver in 1984 by 1.12 years, which is almost an 18 percent drop from a predicted migration duration of 6.3 years for this immigrant.

At 20 years of residence, there is evidence that optimal migration duration decreases in wage ratio at earlier ages in specification 1 , as well as in specification 2 . The rising significance levels in specification 1 are presumably due to the facts that the data are less sparse at 20 years of residence and that the effect of wage ratio depends more on age than duration of residence, unlike it is for ppp. However, this finding is not robust at all: 
in specifications 4 and 5, both the statistical significance and the magnitude of the wage ratio variable are quite low at all values of age at arrival. Moreover, in specifications 4 and 5 , the coefficients of the wage ratio variable at all age-at-arrival values are much lower at 20 years of residence than at the time of arrival.

\subsection{Robustness check: restrictions on duration of residence in 1984}

Next, I examine the effect of ppp on optimal migration duration using specification 3 , which does not include any interaction term of ppp. This requires a sample that is more homogenous in terms of duration of residence in 1984 (the initial year of data). Table 4 presents the estimation results for specification 3 using various samples defined according to immigrants' year of arrival in Germany ${ }^{11}$.

In column (1), where immigrants who arrived in Germany in or after 1979 are taken, the estimate for ppp, at -29.5, is similar to that for ppp at zero duration of residence in specification 2 in Table 3. As we relax the restriction on year of arrival and increase the sample size, while the magnitude of ppp coefficient decreases, its statistical significance increases. In column (3), where the sample includes those who arrived in Germany in or after 1977, the effect of ppp becomes statistically significant at the 10 percent level despite the very small sample size. Moreover, the magnitude of the coefficient, at -16.6, is still similar to the estimates for the effect of ppp at arrival in specifications 1 and 2 in Table 3. When we increase the sample even more by including all immigrants who arrived in 1973 or later, the statistical significance rises to the 5 percent level. However, in consistence with the findings in Table 3, where the effect of ppp diminishes by duration of residence, the effect of ppp in Table 4 also diminishes as we increase the sample size by including immigrants with longer duration of residence.

Table 4 Estimates for specification 3, with restrictions on duration of residence in 1984

\begin{tabular}{|c|c|c|c|c|c|c|}
\hline \multicolumn{7}{|c|}{ Dependent variable: intended migration duration } \\
\hline Year of Arrival & $>=1979$ & $>=1978$ & $>=1977$ & $>=1973$ & $>=1972$ & $>=1971$ \\
\hline & (1) & (2) & (3) & (4) & (5) & (6) \\
\hline \multirow[t]{2}{*}{ Log(PPP) } & -29.516 & -14.361 & $-16.612^{*}$ & $-9.851^{* *}$ & $-5.530^{*}$ & $-4.235^{*}$ \\
\hline & [12.948] & {$[6.447]$} & [6.399] & {$[2.677]$} & {$[2.142]$} & [1.370] \\
\hline \multirow[t]{2}{*}{ Wage ratio } & -55.686 & -44.031 & -49.598 & 7.034 & $16.561^{* * *}$ & $16.229 * * *$ \\
\hline & [47.953] & [36.894] & [40.443] & [6.952] & {$[1.730]$} & {$[1.144]$} \\
\hline \multirow[t]{2}{*}{ Wage ratio* age } & -0.259 & 0.174 & 0.79 & -0.607 & -0.529 & $-0.518^{*}$ \\
\hline & {$[1.656]$} & [1.143] & {$[1.623]$} & {$[0.421]$} & {$[0.241]$} & {$[0.210]$} \\
\hline \multirow[t]{2}{*}{ Dur. of residence } & 5.304 & 5.574 & $6.243^{*}$ & $4.216^{* *}$ & $4.141^{* *}$ & $3.930^{* *}$ \\
\hline & [3.359] & {$[2.484]$} & {$[2.416]$} & {$[0.733]$} & {$[0.912]$} & {$[0.870]$} \\
\hline \multirow[t]{2}{*}{ Age * dur. of residence } & -0.063 & -0.074 & $-0.090^{*}$ & $-0.040^{*}$ & $-0.041^{*}$ & $-0.038^{*}$ \\
\hline & {$[0.050]$} & {$[0.042]$} & {$[0.036]$} & {$[0.013]$} & {$[0.017]$} & {$[0.016]$} \\
\hline \multirow[t]{2}{*}{ Married } & $-11.398^{* * *}$ & 1.547 & -1.194 & $-2.083^{*}$ & $-2.215^{* * *}$ & $-2.782^{* * *}$ \\
\hline & {$[1.550]$} & {$[8.965]$} & [7.302] & {$[0.869]$} & {$[0.107]$} & [0.184] \\
\hline Observations & 265 & 332 & 426 & 1,232 & 1,654 & 2,100 \\
\hline Number of people & 44 & 52 & 64 & 158 & 214 & 280 \\
\hline R-squared & 0.357 & 0.34 & 0.333 & 0.211 & 0.195 & 0.197 \\
\hline
\end{tabular}


Table 5 presents the effect of wage ratio on intended migration duration for specification 3, calculated as linear combinations of the terms including wage ratio in Table 4. When the sample is restricted to those who arrived in or after 1979 in column (1), there is strong statistical evidence for a large and negative effect of wage ratio on intended migration duration, in particular at earlier ages. However, as the sample is enlarged by including earlier arrivers, as can be seen in columns (2) to (6), both the magnitude and statistical significance of the effect of wage ratio gradually diminish. The results presented in Table 5 point out a much stronger influence of duration of residence on the effect of wage ratio than those presented in panel (b) of Table 3.

In essence, Table 5 provides evidence for a strong negative effect of wage ratio on intended migration duration for immigrants with short duration of residence. On the other hand, the effect of wage ratio on intended migration duration calculated for the time of arrival in panel (b) of Table 3 is lower in magnitude. (It is consistent in sign and also statistically significant at certain ages, though.) Therefore, we can conclude that there is suggestive, but not conclusive, evidence on a negative effect of wage ratio on intended migration duration.

\subsection{Who would stay longer: immigrants from poorer or relatively wealthier countries?}

The above findings imply that immigrants from poorer countries may stay shorter in the host country if the impact of a higher ppp in decreasing migration duration dominates the impact of a lower wage ratio in increasing migration duration. To examine this, I calculate the predicted migration duration, according to country of origin, for an unmarried immigrant arriving at Germany at various ages (20, 30, and 40) in 1984, which is presented in panel (a) of Table 6. The key finding is that-holding all individual characteristics constant-the predicted migration duration of an immigrant facing Turkish ppp and wage ratio values is shorter than those of immigrants facing ppp and wage ratio values of EU countries for all three age-at-arrival groups. In other words, the shortest intended migration duration occurs when the ppp and wage ratio values are taken for the poorest country in the sample.

Table 5 Impact of wage ratio on intended migration duration - specification 3

\begin{tabular}{|c|c|c|c|c|c|c|}
\hline Year of arrival & $>=1979$ & $>=1978$ & $>=1977$ & $>=1973$ & $>=1972$ & $>=1971$ \\
\hline Age & (1) & (2) & (3) & (4) & (5) & (6) \\
\hline \multirow[t]{2}{*}{20} & $-60.872 * *$ & $-40.541 *$ & $-33.807 * *$ & $-5.114 * *$ & 5.990 & 5.873 \\
\hline & {$[16.147]$} & [16.181] & [8.304] & [1.473] & [3.083] & [3.713] \\
\hline \multirow[t]{2}{*}{25} & $-62.168 * * *$ & $-39.669 * *$ & $-29.859 * * *$ & -8.151 & 3.348 & 3.284 \\
\hline & [9.685] & [12.260] & {$[2.563]$} & [3.568] & {$[4.286]$} & {$[4.737]$} \\
\hline \multirow[t]{2}{*}{30} & $-63.465 * * *$ & $-38.797 * *$ & $-25.912 *$ & -11.188 & 0.705 & 0.696 \\
\hline & [7.997] & [10.203] & {$[8.710]$} & {$[5.669]$} & {$[5.490]$} & [5.771] \\
\hline \multirow[t]{2}{*}{35} & $-64.762 * *$ & $-37.924 * *$ & -21.964 & -14.225 & -1.937 & -1.892 \\
\hline & [13.085] & [11.100] & [16.640] & [7.771] & [6.693] & {$[6.811]$} \\
\hline \multirow[t]{2}{*}{40} & $-66.058 * *$ & $-37.052 *$ & -18.016 & -17.262 & -4.579 & -4.481 \\
\hline & [20.386] & [14.410] & [24.690] & [9.873] & [7.896] & [7.853] \\
\hline \multirow[t]{2}{*}{45} & $-67.355^{*}$ & -36.180 & -14.069 & -20.299 & -7.222 & -7.070 \\
\hline & [28.232] & [18.905] & {$[32.772]$} & [11.975] & {$[9.099]$} & {$[8.898]$} \\
\hline
\end{tabular}

Notes: Estimates are linear combinations of parameters presented in Table 4. Robust standard errors in brackets; ${ }^{*}$ significant at $10 \%$; ${ }^{* *}$ significant at $5 \%$; ${ }^{* *}$ significant at $1 \%$. 
Table 6 Predicted intended migration durations

\begin{tabular}{ccccc}
\hline & Turkish & Greek & Italian & Spanish \\
\hline A) Duration of residence $=$ & & & & \\
Age at arrival $=20$ & 7.29 & 10.08 & 11.38 & 10.90 \\
Age at arrival $=30$ & 3.64 & 7.73 & 10.36 & 9.05 \\
Age at arrival $=4$ & 00.00 & 5.38 & 9.34 & 7.20 \\
\hline B) Duration of residence $=10$ & & & & \\
Age at arrival $=20$ & 31.04 & 31.66 & 30.58 & 31.62 \\
Age at arrival $=30$ & 24.27 & 26.18 & 26.43 & 26.65 \\
Age at arrival $=40$ & 20.63 & 23.83 & 25.41 & 24.79 \\
\hline C) Duration of residence $=20$ & & & & \\
Age at arrival $=20$ & 61.05 & 59.49 & 56.03 & 58.60 \\
Age at arrival & $=30$ & 54.28 & 54.02 & 51.88 \\
Age at arrival $=40$ & 47.51 & 48.54 & 47.74 & 48.64 \\
\hline
\end{tabular}

Notes: Est imates are based on the parameters in specification 1 in Table 2. The predicted migrat ion durat ions are given for an immigrant who arrives in Germany in 1984 and who is unmarried.

These predictions are also given at 10 and 20 years of residence in panels (b) and (c) of Table 6, respectively. Although the migration duration is the shortest for Turks among 20 -year-old arrivers at the time of arrival, the migration duration for Turks is not shorter among 20-year-old arrivers at 10 years of residence, and is in fact higher among 20-yearold arrivers at 20 years of residence. This points out different selection dynamics in return migration across country of origin groups; as immigrants with stronger return intentions actually return within the first 20 years of residence, the intended migration duration of the remaining immigrants increases, and this selection takes place at a higher pace for Turkish immigrants.

It is important to note that this finding can be generalized. According to our estimates in Table 2, the predicted migration duration of an unmarried 20-year-old immigrant originating from a poorer source country for which ppp is 2 and wage ratio is 0.25 (wage ratio at ppp is 0.5 ) is shorter - at 5.9 years - than the predicted migration duration of such an immigrant originating from a country for which ppp is 1.5 and wage ratio is 0.5 (wage ratio at ppp is 0.75 ) - at 9.3 years - which in turn is shorter than the predicted migration duration of such an immigrant originating from a relatively wealthier source country for which ppp is 1.25 and wage ratio is 0.75 (wage ratio at ppp is 0.9375 ) - at 10.9 years.

The finding that the intended migration duration of immigrants facing Turkish values for ppp and wage ratio is shorter at arrival may be surprising at first because the literature is full of evidence on the fact that actual return rates of Turkish immigrants are in fact lower. The critical issue here is that my predictions are based on varying ppp and wage ratio levels, but holding individual characteristics constant. However, Turkish immigrants were different at arrival in terms of certain individual characteristics that influence return migration decisions; for instance, Turkish immigrants were slightly older than the EU immigrants and much more likely to be married and have children at the time of their arrival. Moreover, the findings of the earlier empirical literature suggest that Turkish immigrants were different from EU immigrants in important unobserved characteristics because the self-selection in the immigration decision to Germany was substantially different between Turkish and EU immigrants. While immigrants from EU countries were more likely originate from rural areas, many Turkish immigrants-in particular those in the earlier waves-belonged to the skilled or semi-skilled workforce 
in Turkey (Paine 1974). In fact, an analysis of education levels of immigrants by their source countries, using the data for 1984 in the GSOEP, shows very similar average educational attainment by country of origin, despite the much lower average educational attainment in Turkey compared to that in the three EU countries.

\subsection{Robustness check: return intention as a dummy variable}

As explained in the data section, although the return intention dummy variable is available for 7,154 person-year observations for 827 immigrants in the sample, the intended migration duration variable is available for 6,099 person-year observations for 813 immigrants. Therefore, I check the robustness of my findings by conducting the same analysis for the return intention dummy variable. On one hand, the use of return intention dummy variable prevents any potential sample selection bias that might result from non-random non-response to the intended migration duration question; on the other hand, the return intention dummy variable obviously contains less information than the intended migration duration variable.

The estimation results, presented in Tables 7 and 8, support the previous findings regarding the effects of ppp and wage ratio variables. For instance, according to the first specification, a 10 percent increase in ppp increases the return intention probability of a 30 -year-arriver at the time of his arrival by 5.2 percentage points, from a baseline level of 87.1 percent in 1984. Also consistent with the previous findings are that the effect of ppp is stronger for later arrivers, and that there is no evidence of an effect of ppp on return intention probability at 20 years of residence.

\section{Conclusions}

This paper examines the effects of purchasing power parity and relative wages between the host and source countries on immigrants' optimal migration duration by first developing a simple theoretical framework that allows for heterogeneity across immigrants according to their willingness to substitute consumption intertemporally, and then testing certain comparative statics implications of this framework using a longitudinal data set on immigrants in Germany from four different source countries.

The theoretical model shows that although it is not analytically possible to sign the effect of ppp on optimal migration duration, given the values of the elasticity of intertemporal substitution of consumption uncovered by the previous literature, optimal migration duration would decrease in ppp, as claimed by Stark et al. (1997) for a more specific case. In the case that immigrants do not work as wage earners after returning to their home country, which has strong empirical relevance, optimal migration duration always decreases in ppp.

The empirical analysis confirms that ppp has a negative impact on optimal migration duration and the magnitude of this impact is large; for instance, a 10 percent increase in ppp reduces the predicted migration duration at the time of arrival by 20 percent for an immigrant who arrives in Germany at the age of 20. The magnitude of this impact is even larger for immigrants who arrive at later ages. The empirical results also suggest that optimal migration duration decreases as the ratio of home country wage rate to host country wage rate increases, which confirms the implication of the theoretical model on this issue. 
Table 7 Fixed-effects OLS estimates for return intention dummy variable

\begin{tabular}{|c|c|c|c|c|}
\hline \multicolumn{5}{|c|}{ Dependent variable: return intention dummy variable } \\
\hline & Specification 1 & Specification 2 & Specification 4 & Specification 5 \\
\hline \multirow[t]{2}{*}{ Log(PPP) } & -0.120 & $0.594^{* * *}$ & -0.278 & -0.435 \\
\hline & {$[0.330]$} & {$[0.091]$} & {$[0.283]$} & {$[0.241]$} \\
\hline \multirow[t]{2}{*}{$\log (P P P) *$ age } & 0.021 & & $0.022^{*}$ & $0.022^{* *}$ \\
\hline & {$[0.011]$} & & {$[0.007]$} & {$[0.006]$} \\
\hline \multirow[t]{2}{*}{$\log (P P P) *$ dur. of res. } & $-0.048^{*}$ & $-0.032^{* * *}$ & $-0.051^{* *}$ & $-0.047^{* * *}$ \\
\hline & {$[0.015]$} & {$[0.004]$} & [0.009] & {$[0.008]$} \\
\hline \multirow[t]{2}{*}{ Wage ratio } & -0.227 & -0.038 & -0.178 & -0.370 \\
\hline & {$[0.330]$} & {$[0.226]$} & {$[0.337]$} & {$[0.406]$} \\
\hline \multirow[t]{2}{*}{ Wage ratio* age } & -0.002 & 0.000 & 0.002 & 0.003 \\
\hline & {$[0.019]$} & {$[0.005]$} & {$[0.015]$} & {$[0.015]$} \\
\hline \multirow[t]{2}{*}{ Wage ratio * dur. of res. } & 0.013 & & -0.002 & -0.002 \\
\hline & [0.029] & & {$[0.026]$} & [0.022] \\
\hline \multirow[t]{2}{*}{ Dur. of residence } & -0.012 & -0.008 & $-0.072^{* * *}$ & $-0.075^{* * *}$ \\
\hline & {$[0.012]$} & {$[0.006]$} & {$[0.008]$} & {$[0.006]$} \\
\hline \multirow[t]{2}{*}{ Age $^{*}$ dur. of residence } & 0.000 & 0.000 & $0.000^{* *}$ & $0.000^{* * *}$ \\
\hline & {$[0.000]$} & {$[0.000]$} & {$[0.000]$} & {$[0.000]$} \\
\hline \multirow[t]{2}{*}{ Married } & $0.055^{*}$ & $0.051^{*}$ & $0.060^{* *}$ & $0.059^{*}$ \\
\hline & [0.019] & [0.018] & [0.019] & [0.019] \\
\hline \multirow[t]{2}{*}{ Home country growth rate } & & & & $-0.062^{* *}$ \\
\hline & & & & {$[0.012]$} \\
\hline \multirow[t]{2}{*}{ Home country growth rate * age } & & & & $0.000^{* * *}$ \\
\hline & & & & {$[0.000]$} \\
\hline \multirow[t]{2}{*}{ Home country growth rate * dur. of res. } & & & & $0.002^{* *}$ \\
\hline & & & & {$[0.000]$} \\
\hline Year dummies & No & No & Yes & Yes \\
\hline Observations & 7.154 & 7.154 & 7.154 & 7.154 \\
\hline Number of people & 827 & 827 & 827 & 827 \\
\hline R-squared & 0.042 & 0.041 & 0.050 & 0.052 \\
\hline
\end{tabular}

Notes: Standard errors are adjusted for clustering at the level of country of origin. Macro variables are three-year moving averages. Robust standard errors in brackets; * significant at 10\%; ${ }^{* *}$ significant at 5\%; *** significant at $1 \%$.

While some immigrants originate from poor countries, other immigrants come from countries with relatively similar characteristics to those of the host country. For instance, are intra-European immigrants from high wage and low ppp countries or immigrants from developing countries with low wage and high ppp more likely to stay longer? The empirical analysis in this study shows that holding individual characteristics constant, an immigrant facing Turkish ppp and relative wages stays shorter in Germany than an immigrant facing ppp and wage ratio values of the wealthier three EU countries in the sample; in other words, immigrants from the poorest country in the sample stay shorter. This finding also implies that a reduction in the economic disparity between Germany and Turkey would lead to a longer migration duration for Turkish immigrants in Germany. Similarly, economic growth in Mexico and the Philippines could lead to longer migration durations for Mexican immigrants in the U.S. and Philippine immigrants in Saudi Arabia, respectively.

An important issue is obviously the transferability of the empirical findings of this paper to other geographical settings at different times. The empirical results of this paper are for temporary migrants who are in the host country to accumulate savings. This type 
Table 8 Impacts of PPP and wage ratio on return intention dummy variable

\begin{tabular}{|c|c|c|c|c|c|c|c|c|}
\hline \multicolumn{9}{|c|}{ (A) Effect of log(PPP) } \\
\hline & \multicolumn{2}{|c|}{ Specification 1} & \multicolumn{2}{|c|}{ Specification 2} & \multicolumn{2}{|c|}{ Specification 4} & \multicolumn{2}{|c|}{ Specification 5} \\
\hline \multicolumn{9}{|c|}{ Duration of residence $=0$} \\
\hline Age & Coeff & SE & Coeff & SE & Coeff & SE & Coeff & SE \\
\hline 20 & 0.306 & 0.136 & 0.594 & $0.091^{* * *}$ & 0.166 & 0.151 & 0.003 & 0.118 \\
\hline 25 & 0.412 & $0.109 * *$ & 0.594 & $0.091 * * *$ & 0.277 & 0.123 & 0.112 & 0.088 \\
\hline 30 & 0.518 & $0.109 * *$ & 0.594 & $0.091 * * *$ & 0.388 & $0.100 * *$ & 0.222 & $0.058 * *$ \\
\hline 35 & 0.625 & $0.134 * *$ & 0.594 & $0.091^{* * *}$ & 0.499 & $0.088^{* *}$ & 0.331 & $0.030 * * *$ \\
\hline 40 & 0.731 & $0.175^{* *}$ & 0.594 & $0.091^{* * *}$ & 0.610 & $0.089^{* * *}$ & 0.441 & $0.019 * * *$ \\
\hline 45 & 0.838 & $0.223 * *$ & 0.594 & $0.091 * * *$ & 0.721 & $0.105^{* * *}$ & 0.550 & $0.041 * * *$ \\
\hline \multicolumn{9}{|c|}{ Duration of residence $=20$} \\
\hline Age & Coeff & SE & Coeff & SE & Coeff & SE & Coeff & SE \\
\hline 40 & -0.219 & 0.146 & -0.050 & 0.053 & -0.410 & 0.192 & -0.509 & $0.145 * *$ \\
\hline 45 & -0.113 & 0.093 & -0.050 & 0.053 & -0.299 & 0.168 & -0.399 & $0.119 * *$ \\
\hline 50 & -0.007 & 0.049 & -0.050 & 0.053 & -0.188 & 0.148 & -0.290 & $0.097 *$ \\
\hline 55 & 0.100 & 0.050 & -0.050 & 0.053 & -0.077 & 0.135 & -0.180 & 0.081 \\
\hline 60 & 0.206 & 0.095 & -0.050 & 0.053 & 0.034 & 0.132 & -0.071 & 0.076 \\
\hline 65 & 0.313 & 0.148 & -0.050 & 0.053 & 0.145 & 0.138 & 0.039 & 0.082 \\
\hline \multicolumn{9}{|c|}{ (B) Effect of wage ratio } \\
\hline & \multicolumn{2}{|c|}{ Specification 1} & \multicolumn{2}{|c|}{ Specification 2} & \multicolumn{2}{|c|}{ Specification 4} & \multicolumn{2}{|c|}{ Specification 5} \\
\hline \multicolumn{9}{|c|}{ Duration of residence $=0$} \\
\hline Age & Coeff & SE & Coeff & SE & Coeff & SE & Coeff & SE \\
\hline 20 & -0.262 & 0.155 & -0.035 & 0.122 & -0.133 & 0.199 & -0.303 & 0.204 \\
\hline 25 & -0.271 & 0.219 & -0.034 & 0.097 & -0.121 & 0.221 & -0.287 & 0.197 \\
\hline 30 & -0.280 & 0.300 & -0.034 & 0.075 & -0.110 & 0.263 & -0.270 & 0.217 \\
\hline 35 & -0.288 & 0.387 & -0.033 & 0.056 & -0.098 & 0.317 & -0.253 & 0.259 \\
\hline 40 & -0.297 & 0.477 & -0.032 & 0.048 & -0.087 & 0.379 & -0.237 & 0.313 \\
\hline 45 & -0.306 & 0.569 & -0.031 & 0.053 & -0.075 & 0.444 & -0.220 & 0.375 \\
\hline \multicolumn{9}{|c|}{ Duration of residence $=20$} \\
\hline Age & Coeff & SE & Coeff & SE & Coeff & SE & Coeff & SE \\
\hline 40 & -0.042 & 0.112 & -0.032 & 0.048 & -0.120 & 0.198 & -0.276 & 0.132 \\
\hline 45 & -0.051 & 0.041 & -0.031 & 0.053 & -0.108 & 0.193 & -0.260 & $0.107 *$ \\
\hline 50 & -0.059 & 0.094 & -0.031 & 0.069 & -0.097 & 0.215 & -0.243 & 0.129 \\
\hline 55 & -0.068 & 0.184 & -0.030 & 0.091 & -0.085 & 0.257 & -0.226 & 0.182 \\
\hline 60 & -0.077 & 0.278 & -0.029 & 0.115 & -0.074 & 0.312 & -0.210 & 0.246 \\
\hline 65 & -0.086 & 0.372 & -0.029 & 0.140 & -0.063 & 0.373 & -0.193 & 0.316 \\
\hline
\end{tabular}

Notes : Estimates are based on those for specification 1 in Table A1. A t(3) distribution is used in forming the significance levels. ${ }^{* *}$ significant at 1 percent level, ${ }^{* *}$ at 5 percent level, ${ }^{*}$ at 10 percent level.

of migration has been prominent historically, in particular, during the large guestworker recruitment schemes in Europe after the World War II in a period of rapid economic expansion. Similar temporary labor migration policies have been used in the Gulf countries, which drew massive migration from other Middle Eastern and Asian countries in a period of rising oil revenues. Also similar temporary-worker programs have also been proposed in the US. Birdsall et al. (2005) outline how such temporary migration could help both the developing and developed countries. Therefore, the type of migration on which the empirical results of this paper are based on is still important and likely to stay that way, in particular in periods of economic expansions in developed countries. 


\section{Endnotes}

${ }^{1}$ Examining revisions to expectations on mutual-fund investments and changes in the Standard and Poor stock index, Dominitz and Manski (2003) establish a positive association. In addition, van der Klaauw (2012) shows that subjective expectations about future behavior can be valuable in the estimation of structural dynamic choice models; and, Delavande et al. (2011) report that expectations can be useful predictors of future economic decisions also in developing country settings.

${ }^{2}$ Using data both on revisions to intended migration duration and actual return realizations, using the same data set, Dustmann (2003) also reach consistent conlusions as to the relationship between the host country wage rate and migration duration.

${ }^{3}$ The latter is how Tunalı (2000) rationalizes return migration in the context of internal migration.

${ }^{4}$ This would not be true, though, if immigrants had some initial asset holdings. In that case, the level of wages would be important as well.

${ }^{5}$ The typical estimated value of alpha in the life-cycle consumption literature is around -2 (Hubbard et al. 1994). However, a number of recent empirical papers (Keane and Wolpin 2001, Imai and Keane 2004, Sauer 2004) estimate a much higher alpha parameter at around 0.5. Based on experimental studies that estimate risk aversion, Goeree et al. (2003) also estimate alpha around 0.5.

${ }^{6}$ Previously, Djajic and Milbourne (1988) examine the effect of wage levels in either country $\left(y_{h}\right.$ and $\left.y_{g}\right)$, rather than their ratio, on the optimal migration duration in the host country. They find that $\partial d^{*} / \partial y_{h}<0$ and $\partial d^{*} / \partial y_{g} \lesseqgtr 0$.

${ }^{7}$ The source for ppp data is OECD (2002). The wage data in comparison to Germany are taken from the U.S. Bureau of Labor Statistics (2008) for the three EU countries, and from the ILO (2008) for Turkey.

${ }^{8}$ The assumption of independence over time for the error terms is also critical in taking duration of residence as a predetermined variable.

${ }^{9}$ These estimates are calculated as linear combinations of the coefficients of ppp and wage ratio variables with the coefficients of their interactions with age as well as duration of residence, where duration of residence is set at zero and 20, and age is set at various values given in the table.

${ }^{10} \mathrm{~A}$ regression of the return intention dummy variable on age at arrival, duration of residence, marital status, HS and college graduation status, 1974-83 birth-cohort dummy, as well as nationality dummies using 1984 cross-section data shows that return intention increases in age at arrival.

${ }^{11}$ I start with the strongest restriction on year of arrival in Germany that yields a sample large enough for estimation, and gradually relax this restriction.

Competing interests

The IZA Journal of Migration is committed to the IZA Guiding Principles of Research Integrity. The author declares that he has observed these principles.

\section{Acknowledgements}

The comments of the editor, Denis Fougere, as well as three anonymous referees much improved the paper. I would like to thank Abdurrahman Aydemir, Slobodan Djajic, Ozan Eksi, Dean Yang, and seminar participants at METU, TOBB ETÜ, and Bilkent University, and the participants at the European Society of Population Economics conference for their valuable comments. The usual disclaimer holds.

Responsible editor: Denis Fougère

Received: 1 October 2012 Accepted: 9 May 2013 Published: 5 June 2013

\section{References}

Aydemir A, Robinson C (2008) Global labor markets, return and onward migration. Can J Econ 41(4): 1285-1311

Batista C, Vicente PC (2011) Do migrants improve governance at home? Evidence from a voting experiment. World Bank Econ Rev 25(1): 77-104

Birdsall N, Rodrik D, Subramanian A (2005) How to help poor countries. Foreign Aff 84(4): 136-152

Cameron C, Gelbach J, Miller D (2008) Bootstrap-based improvements for inference with clustered errors. Rev Econ, Stat 90(3): 414-427 
Delavande A, Gine X, McKenzie D (2011) Measuring subjective expectations in developing countries: a critical review and new evidence. J Dev Econ 94(2): 151-163

Demurger S, Xu H (2011) Return migrants: the rise of new entrepreneurs in rural china. World Dev 39(10): 1847-1861

Djajic S (1989) Migrants in a guest-worker system: a utility maximizing approach. J Dev Econ 31: 327-339

Djajic S, Milbourne R (1988) A general equilibrium model of guest-worker migration: a source-country perspective. J Int Econ 25: 335-351

Dominitz J, Manski C (2003) How should we measure consumer confidence (Sentiment)? Evidence from the michigan survey of consumers. Working Paper 9926, National Bureau of Economic Research

Dos Santos MD, Postel-Vinay F (2003) Migration as a source of growth: the perspective of a developing country. J Popul Econ 16(1): 161-175

Dustmann C (2003) Return migration, wage differentials, and optimal migration duration. Eur Econ Rev 47: 353-369

Dustmann C, Kirchkamp O (2002) The optimal migration duration and activity choice after Re-migration. J Dev Econ 67: 351-372

Goeree JK, Holt CA, Thomas RP (2003) Risk averse behavior in generalized matching pennies games. Games Econ Behav 45: $97-113$

Harris J, Todaro M (1970) Migration, unemployment and development: a two-sector analysis. Am Econ, Rev 60: 126-142

Hubbard GR, Skinner J, Zeldes SP (1994) The importance of precautionary motives in explaining individual and aggregate saving. Carnegie-Rochester Conf Ser Public Policy 40: 59-125

Imai S, Keane MP (2004) Intertemporal labor supply and human capital accumulation. Int Econ, Rev 45(2): 601-641

International Labor Organization (2008) LABORSTA Database of labour statistics, labour cost in manufacturing. http:// laborsta.lo.org. Accessed 1 May 2008

Jasso G, Rosenzweig M (1982) Estimating the emigration rates of legal immigrants using administrative and survey data: The 1971 cohort of immigrants to the United States. Demography 19: 279-290

Keane MP, Wolpin KI (2001) The effect of parental transfers and borrowing constraints on educational attainment. Int Econ Rev 42: 1051-1104

Kırdar MG (2009) Labor market outcomes, savings accumulation, and return migration. Labour Econ 16(4): 418-428

Kirdar, M G (2012) Estimating the impact of immigrants on the host Country Social security system when return migration is an endogenous choice. Int Econ Rev 53(2): 453-486

Kumcu EM (1989) The savings behavior of migrant workers: turkish workers in W. Germany. J Dev Econ 30: 273-286

Massey D, Espinosa K (1997) What's driving Mexico-US migration? A theoretical, Empirical, and policy analysis. Am J Sociol 102: 939-999

Manski CF (2004) Measuring expectations. Econometrica 72(5): 1329-1376

Mayr K, Peri G (2009) Brain drain and brain return: theory and application to eastern-western Europe. BE J Econ Anal, Policy 9(1): No:49

McCormick B, Wahba J (2001) Overseas work experience, savings, and entrepreneurship amongst return migrants to LDCs. Scott J Pol, Econ 48(2): 164-178

Organization for Economic Development and Cooperation (2002) OECD Indicators, PPP. http://www.oecd.org/std/ purchasingpowerparitiespppsdata.htm. Accessed 1 Sep 2002

Paine S (1974) Exporting workers: the Turkish case. Cambridge University Press, Cambridge

Sauer RM (2004) Educational financing and lifetime earnings. Rev Econ, Stud 71(4): 1189-1216

Sinning MG (2011) Determinants of savings and remittances: Empirical evidence from immigrants to Germany. Rev Econ, Household 9(1): 45-67

Sjastaad L (1962) The costs and returns of human migration. J Pol Econ 70: 80-93

Stark O, Helmenstein C, Yegerov Y (1997) Migrants' savings, purchasing power parity, and the optimal duration of migration. Int Tax Public Finance 4: 307-324

Tunalı i (2000) Rationality of migration. Int Econ Rev 41: 893-920

US Department of Labor (2008) Bureau of Labor Statistics. International Comparisons of Hourly Compensation Costs for Production Workers in Manufacturing, Supplementary Tables. http://www.bls.gov/fls/\#tables. Accessed 1 May 2008

van der Klaauw W (2012) On the use of expectations data in estimating structural dynamic choice models. J Labor Econ 30(3): $521-554$

Yang D (2006) Why do migrants return to poor countries? Evidence from Philippine migrants' responses to exchange rate shocks. Rev Econ, Stat 88(4): 715-735

doi:10.1186/2193-9039-2-8

Cite this article as: KIrdar: Source country characteristics and immigrants' optimal migration duration decision. IZA Journal of Migration 2013 2:8. 